\title{
Morphological study of the attachment of the sternocleidomastoid muscle
}

Anubha Saha ${ }^{1}$, MBBS, MD, Shyamash $\underline{\text { Mandal}}^{2}$, MBBS, MD, Sandip Chakraborty ${ }^{3}$, MBBS, MD, Manimay Bandyopadhyay 4 , MBBs, MS

INTRODUCTION The sternocleidomastoid (SCM) muscle is a major muscle of the neck. Classically, this muscle is attached below the sternum and clavicle, although the mode of attachment might vary. As the SCM is related to numerous important neurovascular structures, its variable anatomy is clinically relevant, particularly for neck surgeries. A cadaveric study was performed to establish the variations present in the mode of attachment of the SCM muscle in an Indian population.

METHODS We studied the variations in the attachment of the SCM muscle during the dissection of 18 cadavers for undergraduate teaching in two medical colleges in West Bengal, India.

RESULTS Variations in the attachment of the SCM muscle were found in $5(27.8 \%)$ specimens. Of these five specimens, three had unilateral variations and two had bilateral variations. In each specimen, the modes of presentation of the SCM and its fusion with the major bulk were also different.

CONCLUSION In this study, we found variations in the attachment of the SCM muscle in more than a quarter of the specimens dissected. Surgeons should bear in mind such variations when performing neck surgeries.

Keywords: anatomical variations, extraclavicular head, sternocleidomastoid muscle

\section{INTRODUCTION}

The sternocleidomastoid (SCM) muscle is a prominent landmark in the neck. It divides the neck into anterior and posterior triangles, and is intimately related to many neurovascular structures. Classically, it has a medial (i.e. sternal) head and a lateral (i.e. clavicular) head. The sternal head is tendinous and arises from the anterior surface of the manubrium sterni, whereas the clavicular head is muscular and arises from the superior surface of the medial third of the clavicle. Both of these heads are separated by a triangular interval, termed the lesser supraclavicular fossa, which corresponds to a surface depression that is used as a clinical landmark for various clinical procedures. As they ascend, the clavicular head spirals behind the sternal head and blends in with its deep surface, forming a thick, rounded belly prior to its insertion into the lateral surface of the mastoid process and the lateral half of the superior nuchal line.(1)

According to Bergman et $\mathrm{al}^{(2)}$ and Sanli et $\mathrm{al}^{\left({ }^{(3)}\right.}$ extensive knowledge of the SCM muscle, which has five parts based on their attachment (namely the superficial sternomastoid, sternooccipital, cleido-occipital, deep sternomastoid and cleidomastoid), is critical to the success of muscle flap harvesting procedures. Detailed knowledge of the variations present in the SCM muscle is essential for surgeons and anaesthetists in order to avoid related complications. While several studies have previously reported variations of the SCM muscle, ${ }^{(3-12)}$ this cadaveric study was conducted to determine, in detail, the variations seen in the mode of attachment of the SCM muscle in a local Indian population.

\section{METHODS}

During routine dissection of cadavers for undergraduate teaching in the anatomy department of Midnapur Medical College and Murshidabad Medical College in West Bengal, India, 18 cadavers were examined for variations in the SCM muscle over a period of two years. Three of the dissected cadavers were female. The SCM muscle was properly exposed after the skin was incised and the covering fasciae removed. Attachments of the muscle were carefully cleaned at both ends. Proper care was taken to preserve the muscle's blood and nerve supply. Measurements were made using a measuring tape and photographs of the specimens were taken.

\section{RESULTS}

We found additional fibres in relation to the SCM muscle in $5(27.8 \%)$ cadavers, all of which were male. Of these, $3(16.7 \%)$ cadavers had unilateral variations and $2(11.1 \%)$ had bilateral variations. Specimens 1-3 were found to have unilateral variations, while specimens 4 and 5 had variations on both sides. All the unilateral variations were noted on the left side. All five cadavers had unique variations that were different from the other specimens.

In specimen 1, there was an additional head attached to the middle of the clavicle, very close to the classical clavicular head and separated by a small gap (Fig. 1). These additional fibres fused with the muscle bulk in the middle, $6.5 \mathrm{~cm}$ above the medial end of the clavicle on the left side. In specimen 2, an additional head of the SCM muscle was found on the left

\footnotetext{
${ }^{1}$ Department of Anatomy, Midnapur Medical College and Hospital, ${ }^{2}$ Department of Medicine, Medical College, ${ }^{3}$ Department of Biochemistry, ${ }^{4}$ Department of Anatomy, Murshidabad Medical College and Hospital, Berhampore, West Bengal, India

Correspondence: Dr Anubha Saha, Sananda, Flat no. A2, 17/1A (1033B/1) Canal South Road, Purbachal, Kasba, Kolkata 700078, West Bengal, India. saha.anubha@yahoo.com
} 


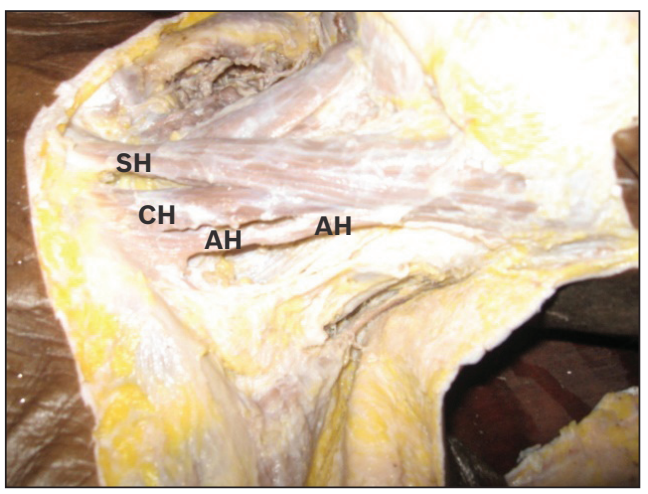

Fig. 1 Photograph of the left lateral view of the neck region shows additional fibres arising close to the clavicular head and fusing with the muscle bulk.

$\mathrm{AH}$ : additional fibres; $\mathrm{CH}$ : clavicular head; $\mathrm{SH}$ : sternal head

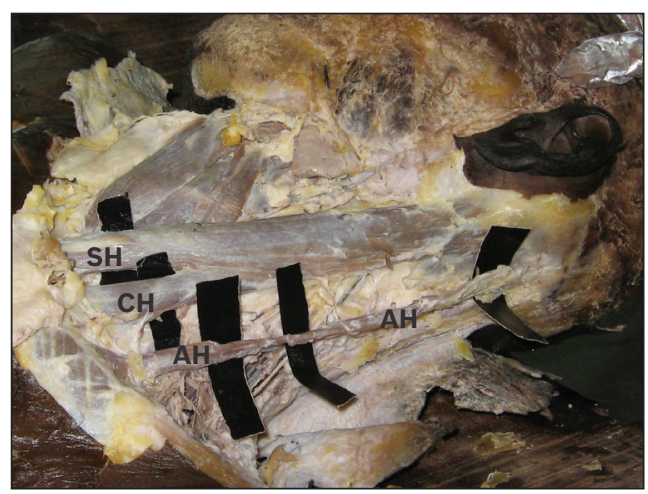

Fig. 3 Photograph of the left lateral view of the neck region shows additional fibres completely separate and parallel to the main sternocleidomastoid muscle.

$\mathrm{AH}$ : additional fibres; $\mathrm{CH}$ : clavicular head; $\mathrm{SH}$ : sternal head

side, quite a distance from the classical clavicular head and $3.0 \mathrm{~cm}$ lateral to it (Fig. 2). The triangular gap between them was larger than the lesser supraclavicular fossa. The additional fibres fused with the muscle bulk close to the mastoid process, $15 \mathrm{~cm}$ above the medial end of the clavicle. In specimen 3, a separate muscle - attached from below to the superior surface of the clavicle, $2 \mathrm{~cm}$ lateral to the clavicular head - was observed on the left side. This thin muscle belly extended vertically upwards, and inserted itself separately into the occipital bone between the SCM and trapezius muscles. It had the appearance of a thin additional muscle, and was parallel and lateral to the SCM muscle (Fig. 3).

Specimen 4 presented with bilateral additional fibres. Two additional clavicular heads were seen on the right side, while three were present on the left side (Fig. 4). All the additional clavicular heads arose from the superior surface of the middle of the clavicle. The distance between each head was $0.5 \mathrm{~cm}$, and the heads fused with the main muscle around its middle, $9 \mathrm{~cm}$ above the medial end of the clavicle. The extra heads made numerous small fossae in the neck and were covered by fascia without any important structures within. In specimen 5, additional fibres were seen on both sides, close to the clavicular head and $0.5 \mathrm{~cm}$ lateral to it. On the left side, these additional fibres fused with the muscle bulk, $13 \mathrm{~cm}$ above the medial end of the clavicle (Fig. 5a), whereas on the

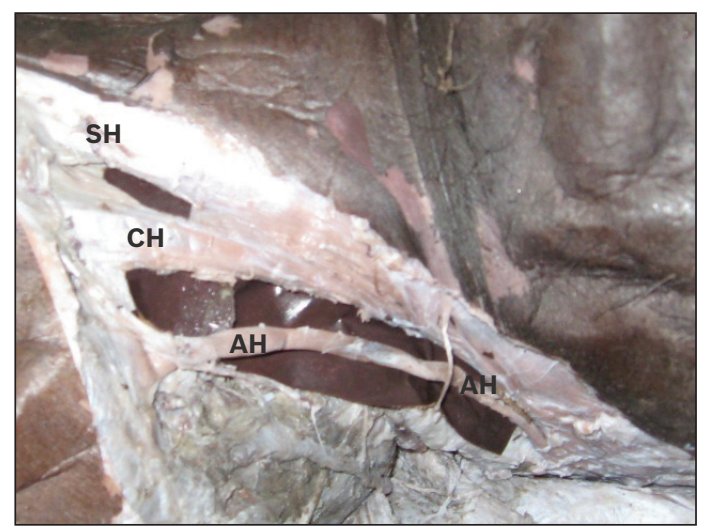

Fig. 2 Photograph of the left lateral view of the neck region shows additional fibres, quite a distance from the classical clavicular head. $\mathrm{AH}$ : additional fibres; $\mathrm{CH}$ : clavicular head; $\mathrm{SH}$ : sternal head

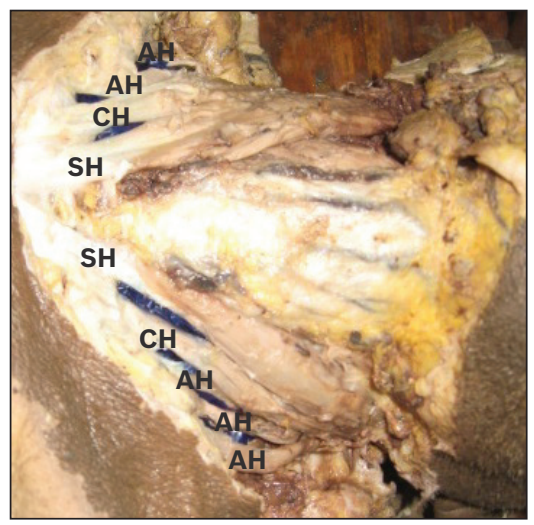

Fig. 4 Photograph of the anterior view of the neck region shows bilateral additional fibres fusing with the muscle bulk.

$\mathrm{AH}$ : additional fibres; $\mathrm{CH}$ : clavicular head; $\mathrm{SH}$ : sternal head

right side, they fused with the muscle bulk, $9 \mathrm{~cm}$ above the medial end of the clavicle (Fig. 5b).

\section{DISCUSSION}

Variations in the attachment of the SCM muscle have been reported by various authors due to the obvious clinical importance of such variations in neck surgeries. ${ }^{(13)}$ However, variations at the upper end of the SCM muscle are rarely reported. ${ }^{(6)}$ The clavicular head of the SCM muscle may be narrow (similar to its sternal head) or wide (measuring up to $7.5 \mathrm{~cm}$ ). ${ }^{(4)}$ Amorim et $\mathrm{al}^{(4)}$ and Hasan ${ }^{(5)}$ have found that a broad clavicular head may be subdivided into several slips. Cherian and Nayak, ${ }^{(6)}$ and Fazliogullari et al ${ }^{(7)}$ reported unilateral leftsided third heads of the SCM muscle from the middle third of the clavicle, while Coskun et al ${ }^{(8)}$ found unilateral sterno-occipital (sternal and clavicular heads), cleidomastoid and sternomastoid fibres in the same cadaver. Interestingly, a study by Boaro et al ${ }^{(9)}$ reported a newborn with topographic variations, where the SCM muscle was found to have four heads - sternal head, clavicular head, fibres from the acromian process, and fibres originating between the clavicular and acromian heads. Bilateral additional slips from the clavicle have also been reported by various authors such as Ramesh et $\mathrm{al}^{(10)}$ and Natsis et al. ${ }^{(11)}$ Separately, Nayak et al ${ }^{(12)}$ reported a rare presentation of additional heads of the SCM originating from 

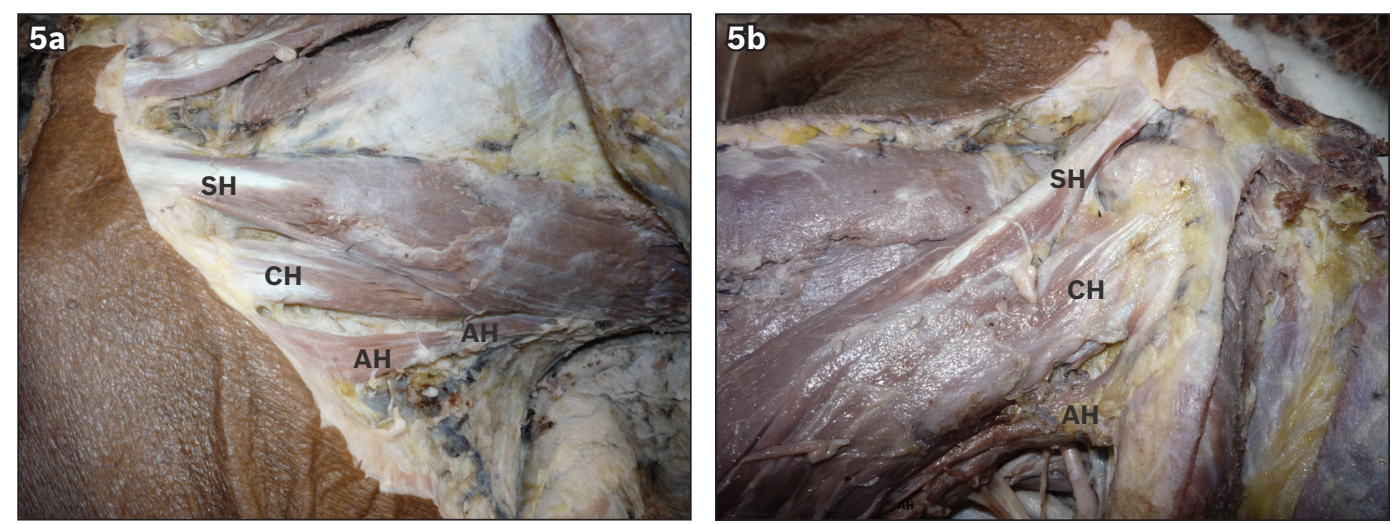

Fig. 5 Photographs of the (a) left and (b) right lateral views of the neck region show bilateral additional fibres. AH: additional fibres; $\mathrm{CH}$ : clavicular head; $\mathrm{SH}$ : sternal head

the capsule of the sternoclavicular joint and superolateral border of the manubrium sterni bilaterally.

In our study, the incidence of extraclavicular heads of the SCM muscle was $27.8 \%$. In four of the five cadavers presenting with SCM variations, the additional fibres joined with the major bulk of the muscle at variable distances, ranging from $6.5 \mathrm{~cm}$ to $15 \mathrm{~cm}$. In only one specimen were the additional fibres found to be completely separated from the main bulk, existing instead as a classical cleido-occipital belly. Unlike our findings, some studies have reported a $33 \%$ incidence of cleido-occipital belly of the SCM muscle. ${ }^{(2,3)}$ The functional advantage afforded by an extra head of the SCM muscle is still unclear. However, in view of the fact that an extra head implies additional muscle fibres, it is possible that such variations may be evolutionary in nature.

Given that the SCM muscle is related to numerous important neurovascular structures in the neck region, detailed knowledge of its variable anatomy is clinically relevant information, as additional clavicular heads might give rise to additional lesser supraclavicular fossae, thus altering the anatomy of the neck. Since central venous catheterisation is mostly attempted through this triangular space, variations in the anatomy of the SCM muscle might lead to difficulties that could create post-procedural complications. As mentioned earlier, Bergman et $\mathrm{a}^{(2)}$ and Sanli et $\mathrm{a}^{(3)}$ have highlighted that detailed knowledge of the SCM muscle is important in muscle flap harvesting. This knowledge also plays an important role in the planning of pedicle muscle flaps for reconstructive or plastic surgeries. Similarly, Conley and Gullane ${ }^{(13)}$ have expounded on the importance of the SCM muscle in the reconstruction of the mandible and mandibular defects, as well as in the reconstruction of the oral floor as a myocutaneous flap. According to some authors, the incidence of Frey's syndrome and facial nerve dysfunction in patients undergoing postoperative parotid surgery may decrease if SCM muscle flaps are used for reconstruction. ${ }^{(10,14)}$ For such procedures, the presence of additional muscle heads might be more relevant, as they would provide better options for the selection of appropriate muscle flaps.
In conclusion, we conducted a cadaveric study to establish the variations present in the mode of attachment of the SCM muscle in a local Indian population. The incidence of extraclavicular heads of the SCM muscle in our cohort was $27.8 \%$, with $2(11.1 \%)$ cadavers having bilateral variations, and $3(16.7 \%)$ having unilateral variations. As detailed knowledge of variations in the SCM muscle is crucial for head and neck surgeons and anaesthetists, clinicians dealing with this region of the body should bear relevant variations in mind when performing such surgical procedures.

\section{REFERENCES}

1. Standring S. Head and Neck. In: Standring S, ed. Gray's Anatomy: The Anatomical Basis of Clinical Practice, 40th ed. London: Elsevier, 2008: 440-1.

2. Bergman RA, Thompson SA, Afifi AK, Saadeh FA. Muscles. In: Bergman RA, Thompson SA, Afifi AK, eds. Compendium of Anatomic Variation Text, Atlas, and World Literature. Baltimore: Urban and Schwarzenberg, 1988: 32-3.

3. Sanli EC, Kurtoglu Z, Ozturk AH, Aktekin M. Detailed anatomy of five parts of the sternocleidomastoid muscle. Neuroanatomy 2006; 5 suppl 2:29.

4. Amorim JR AA, Lins CCSA, Cardoso APS, Damascena CG. Variation in clavicular origin of sternocleidomastoid muscle. Int J Morphol 2010; 28:97-8.

5. Hasan T. Variations of the Sternocleidomastoid Muscle: A Literature Review. The Internet Journal of Human Anatomy 2011, Volume 1 Number 1 [online]. Available at: www.ispub.com/journal/the-internet-journal-ofhuman-anatomy. Accessed June 23, 2012.

6. Cherian SB, Nayak S. A rare case of unilateral third head of sternocleidomastoid muscle. Int J Morphol 2008; 26:99-101.

7. Fazliogullari Z, Cicekcibasi AE, Dogan NU, et al. The levator claviculae muscle and unilateral third head of the sternocleidomastoıd muscle: case report. Int J Morphol 2010; 28:929-32.

8. Coskun N, Yildirim FB, Ozkan O. Multiple muscular variations in the neck region--case study. Folia Morphol (Warsz) 2002; 61:317-9.

9. Boaro SN, Fragoso Neto RA. Topographic variation of the sternocleidomastoid muscle in a just been born children. Int J Morphol 2003; 21:261-4.

10. Ramesh RT, Vishnumaya G, Prakashchandra SK, Suresh R. Variation in the origin of sternocleidomastoid muscle: a case report. Int J Morphol 2007; 25:621-3.

11. Natsis K, Asouchidou I, Vasileiou M, et al. A rare case of bilateral supernumerary heads of sternocleidomastoid muscle and its clinical impact. Folia Morphol (Warsz) 2009; 68:52-4.

12. Nayak SR, Krishnamurthy A, Sj MK, et al. A rare case of bilateral sternocleidomastoid muscle variation. Morphologie 2006; 90:203-4

13. Conley J, Gullane PJ. The sternocleidomastoid muscle flap. Head Neck Surg 1980; 2:308-11.

14. Kerawala CJ, McAloney N, Stassen LF. Prospective randomised trial of the benefits of a sternocleidomastoid flap after superficial parotidectomy. Br J Oral Maxillofac Surg 2002; 40:468-72. 